\title{
First Approach to the Management of Orthopedic Injuries of the Hindfoot
}

\author{
Lázaro Martínez Aparicio, Lázaro Martín Martínez Estupiñan², Juan Carlos Cedré González³, Sergio Morales Piñeiro 4 , Claribel Plain \\ Pazos $^{5}$, Leonardo Domínguez Plain 6 \\ ${ }^{1} 4$ th year resident of Orthopedics and Traumatology, Provincial General University Hospital, Cuba. \\ ${ }^{2}$ Doctor in Medical Sciences, II Degree Specialist in Orthopedics and Traumatology, Full Professor, Provincial General University Hospital, Cuba. \\ ${ }^{3}$ I Degree Specialist in Orthopedics and Traumatology, Assistant Professor, Provincial General University Hospital, Cuba.
}

${ }^{4}$ Provincial General University Hospital "Mártires del 9 de Abril" Sagua la Grande, Cuba.

${ }^{5}$ Specialist of I and II Degree in Comprehensive General Medicine, Faculty of Medical Sciences of Sagua la Grande, Cuba.

${ }^{6}$ Resident of 3rd year of Orthopedics and Traumatology, Provincial General University Hospital, Cuba.

*Corresponding author: Claribel Plain Pazos, Faculty of Medical Sciences of Sagua la Grande, Villa Clara, Cuba.

Received date: January 27, 2021; Accepted date: March 08, 2021; Published date: March 13,2021

Citation: Lázaro M Aparicio, Lázaro M M Estupiñan, Juan C C González, Sergio M Piñeiro, Claribel P Pazos et al. (2021) First Approach to the Management of Orthopedic Injuries of the Hindfoot. Biomedical Research and Clinical Reviews. 3(4); DOI: 10.31579/2692-9406/047

Copyright: (C) 2021 Claribel Plain Pazos, This is an open-access article distributed under the terms of the Creative Commons Attribution License, which permits unrestricted use, distribution, and reproduction in any medium, provided the original author and source are credited.

\section{Abstract}

Hindfoot pain is a common clinical problem that can be due to multiple alterations, it can appear due to bone or soft tissue causes, it is established in a small anatomical area. There are different methods of treatment for these conditions, ranging from simple guidelines in lifestyle to surgery. In this work, patients are divided into four groups with different treatment methods, each group was assigned a different therapeutic option, which will increase its degree of invasion as the number of the group increases. Infiltration with platelet-rich plasma (PRP) is a new technique of cell regenerative therapy and was applied in one of the groups, taking advantage of the regenerative, healing and anti-inflammatory properties of the mentioned therapy.

Key words: hindfoot pain; hindfoot injury management; plasmarichin platelet

\section{Introduction}

The skeleton of the foot consists of three parts: the tarsus, the metatarsal, and the phalanges. The tarsus has bones like, calcaneus and talus. The calcaneus is the longest of the tarsal bones. It is located at the bottom and back of the foot, helping to transmit the weight of the body to the ground, and forming a firm lever for the leg muscles. It is an irregular bone with a cuboid shape, directing its axis along the foot and presenting six surfaces for examination. The talus is the second largest bone in the foot. It occupies the middle and upper part of the tarsus, supporting the tibia, resting on the calcaneus, articulating on each side with the malleoli, and on the front with the navicular [1].

The calcaneus is the largest bone in the foot, it is unique in the human race to maintain the erect position, it is responsible for the plantigrade position and the posterior lever on which the triceps suralis inserted, it is a spongy bone, formed by a cortical periphery thicker inside and an internal trabecular system.

Pain in the hindfoot is a frequent clinical problem that can be caused by multiple alterations, bone and soft tissue that are in the anatomical area, which require an accurate and sometimes a difficult clinical diagnosis. A clinical diagnosis together with radiology allows determining the exact location and extention of the lesion. Multiple alterations include hindfoot pain from: bone lesions, tendon lesions, altered bursae, sole fasciae, sinus tarsal syndromes, and bone and soft tissue tumors [2].

The purpose of this study is to characterize the clinical and epidemiological character of the patients suffering from any orthopedic lesion of the hindfoot and the efficacy of the applied therapeutic option.

\section{Method}

A prospective, longitudinal intervention study was conducted at Sagua La Grande University General Hospital in the orthopedic and traumatology consultation, developed between January 1, 2019 and January 1, 2020. The research included patients diagnosed with a hindfoot lesion, at random, in four groups with different therapeutic options, with the aim of comparing the results and differentiating which therapeutic option offers the best clinical evolution and the improvement of the patients.

The patients, after being diagnosed with a hindfoot condition, were included in one of the groups created to be assisted, depending on the doctor`s consideration about signs and symptoms evolution. The doctor will estimate the convenience of any of the therapeutic options that are included in the research. Each group will be assigned a different therapeutic option, which will increase the degree of invasion as the number of the group increases. 
Group \# 1: Physical rest and the reduction or elimination to last and guide for 3 weeks, combined with cryotherapy in the region of the hindfoot where the injury is for a maximum of 15 minutes, with a frequency of no more than 4 hours between sessions and session. The use of suitable footwear and physiotherapy.

Group \# 2: Physical rest and the reduction or elimination of the cause, for two weeks, combined with cryotherapy in the region of the hindfoot where the injury is for a maximum of 15 minutes, with a frequency of no more than 4 hours between sessions and chapter. It also includes the use of oral analgesics and anti-inflammatory drugs, for 1 week, with a maximum of 10 days.

Group \# 3: Physical rest and the reduction or elimination of aggressions for two weeks, combined with cryotherapy in the hindfoot region for a maximum of 15 minutes, with a frequency of no more than 4 hours between sessions. Additionally, the use of depot steroid injection; Triancinolone Acetateis suggested.

Group \# 4: Physical rest and the reduction or elimination of aggressions, for two weeks, combined with cryotherapy in the posterior region of the foot, with a maximum of 15 minutes, with a frequency of no more than four hours between sessions. Autologous infiltration of PRP, obtained from the same patient and prepared the same day of the consultation,is also incorporated. Infiltration of three doses in three weeks issuggested.

The ethical conditions were taken into account through the four basic principles of research in human subjects: beneficence, proper conduct, justice and respect. Written informed consent was applied to the patients who participated in the study. The information was coded using an information collection model so that the names of the patients are known only by the research team.

\section{Results}

Table \# 1 shows the distribution of the main orthopedic pathologies that affect the hindfoot, we found that the calcaneal spur was the most common condition, with 38 cases, representing $27.33 \%$, similar to sole fasciitis or calcification. Tarsal tunnel syndromewasthe least frequent pathology found, with only two cases, representing $1.43 \%$.

\begin{tabular}{|l|l|l|}
\hline Pathologies found & Cases & \% of all cases \\
\hline Spur Heel & 38 & 27.33 \\
\hline Sole fasciitis or calcification & 38 & 27.33 \\
\hline Haglund's deformity & 15 & 10.79 \\
\hline Retro-calcaneal bursitis & 13 & 9.35 \\
\hline $\begin{array}{l}\text { Fibula and flexor muscle, tibial tendons rear } \\
\text { mess }\end{array}$ & 10 & 7.19 \\
\hline Achilles tendon insight tendonitis & 9 & 6.47 \\
\hline Achilles tendon calcification & 8 & 5.75 \\
\hline Tarsal entrapment & 6 & 4.31 \\
\hline Tarsus tunnel syndrome & 2 & 1.43 \\
\hline Total & 139 & 100.00 \\
\hline
\end{tabular}

Table 1. The distribution of the main orthopedic pathologies of the hindfoot.

Table 2: shows the therapeutic options divided into four groups, which increase their degree of intensity according to the patient's conditions. Group 2 is the one with the largest number of patients [67 cases included],

2 is the one with the largest number of patients [67 cases included], poorly.
\begin{tabular}{|l|l|l|l|l|l|}
\hline Therapeutic options & Patients & $\%$ & Evolution & Regular \\
\cline { 3 - 7 } & & & Good & & \\
\hline Group \# 1 & 38 & 27.33 & 21 & 8 & 9 \\
\hline Group \# 2 & 67 & 48.20 & 52 & 8 & \\
\hline Group \# 3 & 21 & 15.10 & 18 & 2 & \\
\hline Group \# 4 & 13 & 9.37 & 12 & 1 & \\
\hline Total & 139 & 100 & 103 & 19 & 1 \\
\hline
\end{tabular}

Table 2. Evolution of group of patients according to the treatment.

\section{Discussion}

The main anatomical origin of painful areas in the hindfoot include the calcaneus, sole fascia, various tendons [the Achilles tendon, the flexor longus muscle of the first toe, the flexor longus muscle of the first toe], the tarsal tunnel, bursae, and the foot pad $[2,3]$.

The painful heel is frequently caused by insertional tendinopathy and occurs more frequently in adults, patients refer to overuse or repetitive trauma, in patients the spondyle arthritis and sero-negative rheumatoid arthritis. It consists of a focal tendinopathy in the distal portion at the insertion point in the calcaneus bone and is frequently associated with the formation of enthenopathy and calcifications within the tendon. corresponding to $48.20 \%$ of all cases. We must point out that if the evolution is observed in group 4 , there are no patients who improve poorly.

Alterations of tendon insertion include tendinosis and partial thickness ruptures, often bursitis appears here. When a protruding part of the calcaneus bone appears in the posterior area or exostosis, it is called Haglund's deformity [4].

The therapeutic management of orthopedic conditions in the hindfoot is initiated with the appropriate choice and correct execution of the treatment, which aims to control the symptoms with alternatives that range from conservative treatments, minimally invasive treatments, to surgical treatment as the last option. There are many conservative treatments for these conditions, they are used alone or in combination, but many of them without scientific basis and with little efficacy. They include cryotherapy, anti-inflammatories, or extracorporeal shock waves, like physical therapy, eccentric exercise. In some patients, symptoms 
persist despite conservative management; surgical management is required then.

The local injection of inflammatory agents is controversial due to the risk of tendon rupture and atrophy of the fatty substance of the subcutaneous cellular tissue. At present, there are several therapeutic options and the local administration of growth factors is an emerging treatment strategy, platelet-rich plasma [PRP] has been introduced in clinical practice to process an increasing number of different skeletal pathologies and especially in hindfoot orthopedic diseases $[5,6]$.

\section{Conclusions}

There are multiple injuries that affect the hindfoot of the adult, therefore it is necessary to protocolthe management, although they differ greatly, and evaluate the benefits of each treatment and the possibilities for improvement they give, an important information when facing these injuries. The use of platelet-rich plasma applications in a higher percentage of patients as a treatment is a viable option.

The contribution of the authors: The authors took part in the application of the treatments, the writing of the work and the analysis of the documents.
Conflicts of interest: There are no conflicts of interest.

\section{References}

1. James B, James S, Wayner R, Osternig L, Li-Shan Chou. Biomechanical Factors Associated With Achilles Tendinopathy and Medial Tibial Stress Syndrome in Runners. American Journal of Sports Medicine. 2017; 45 [11]: 2614-21..

2. Damiano J. (2018) Talalgias. EMC - Aparato Locomotor.;51[2]:17.

3. Damiano J.Patología de la aponeurosis plantar. EMC - Podología. 2018;20[4]:1-13.

4. Bueno Palomino A, García Sánchez E, Alfaya Jiménez AM, Mora Artiga E. (2016) Síndrome de Haglund con espolón calcáneo posterosuperior asociado: a propósito de un caso. Rehabilitación.;50[1]:50-53.

5. Rienzi A, MIller A, Cuevas I. (2016) Platelet-rich plasma. Indications in sports injuries. Trends in Medicine. 48: 145-51.

6. Tormo Collado F, Mifsut Miedes D. (2017) Infiltration of autologous PRP as a treatment for chronic tendinopathies of the Achilles tendon. Spanish Journal of Osteoarticular Surgery. 269 [52]: 18-27.
This work is licensed under Creative Commons Attribution 4.0 License

To Submit Your Article Click Here: Submit Manuscript

DOI: $10.31579 / 2692-9406 / 047$
Ready to submit your research? Choose Auctores and benefit from:

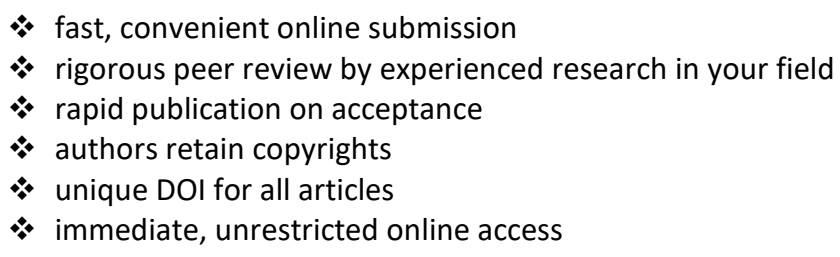

At Auctores, research is always in progress.

Learn more www.auctoresonline.org/journals/international-journal-ofclinical-case-reports-and-reviews 